\title{
Empirical Study on the Effect of Flexibility on Machinery Manufacturing
}

\author{
SongQing $\mathrm{Li}^{1, \mathrm{a}^{*}}$, WeiLing $\mathrm{Wu}^{2, \mathrm{~b}}$ \\ ${ }^{1}$ Business College, Hunan Agricultural University, Hunan, China,410128 \\ ${ }^{2}$ Business College, Hunan Agricultural University, Hunan, China,410128 \\ alisongqing6789@163.com, byiling8898@163.com \\ * WeiLing $\mathrm{Wu}$
}

Keywords: Manufacturing; Flexible factors; Business strategy

Abstract. This article select 30 listed companies in machine,equipment and instrument manufacturing as study object.AHP is used to created a hierarchical network model about company flexible, Catastrophe progression method and regression analysis prediction method is uesed to analysis the degree that how flexibility infuence business performance. The conclusion of this article tell us that: The ordering of flexiblity is research and development flexiblity,marketing flexiblity,resource flexiblity,operations flexiblity and capital flexiblity.

\section{Introduction}

Flexibility is the ability to response effectively (Mandelbaum,1978).Flexibility decision has a positive effect on business performance. However, the kind of literature with empirical analysis is not very common to be observed, which focuses on the flexibility factors and the impacts of flexibility decision.

\section{The establishment and basic ass umptions of enterprises' flexibility strategy}

Based on previous researchachievement and current situations of Chinese manufacturing industry, 5 main flexibilities are used to build an enterprise's flexibility system. And the 5 flexibilities are resources flexibility, operation flexibility,, R\&D flexibility and market flexibility.

1. Basic assumption

H0: Flexibilities of enterprises' resources, operation, capital structure, R\&D and market have remarkable effect on business performance.

H1:Flexibilities of enterprises' resources, operation, capital structure, $R \& D$ and market do not have remarkable effect on business performance.

\section{Empirical study}

Model Specification

These factors above are used to construct a regression equation, and the business performance is regarded as the explained variable while the enterprise flexibility as the explaining variable. The details is shown in Table 1. 
Table 1 Variable Definition

\begin{tabular}{llll}
\hline Property & Name & Symbol & Description \\
\hline Explained variable & Business performance & NPG & Net profit growth rate \\
Explaining variable & Resources flexibility & RF & Resources occupancy \& opention capability \\
& Operation flexibility & OF & Capital operation ability \\
& Capital structure flexibility & CSF & The ability of capital structure adjustment \\
& R\&D flexibility & RDF & R\&D inves tment \\
& Market flexibility & MF & Market adjusted ability \\
\hline
\end{tabular}

Derived from hypothesis $\mathrm{H} 0$, theregressionequation is obtained below.

$N P G=a R F+b O F+c C S F+d R D F+e M F+f$

The definitions of $N P G, R F, C S F, R D F$ and $M F$ are listed in the table above, and $f$ is a constant term.

Indicator selection and Date processing

The net profit growth rate is used as an indicator to reflect business performance, and a three-hierarchical network model about flexiable decision-making is shown in Fig 1.

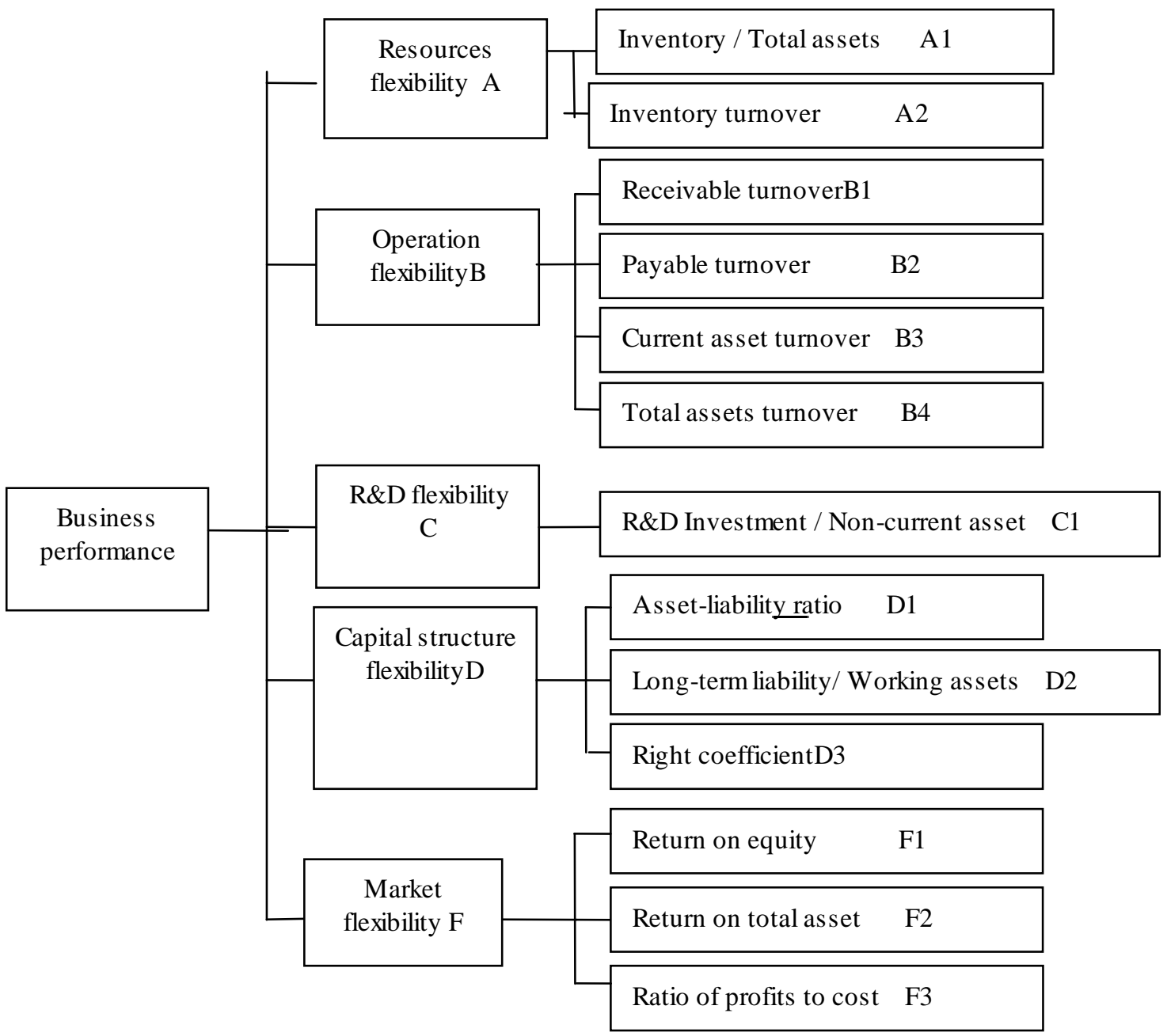

Fig 1 Flexible factor system diagram

There are 3 common mutation coefficient models:(1)The cusp mutation system, whichcontains 2 sub-indexes. The model form is $f(x)=x 4+a x 2+b x$ and the formula is $x a=a^{\wedge}(1 / 2), x b=b^{\wedge}(1 / 3)$. (2) The coattail catastrophe model, containing 3 sub-indexes. The model form is $f(x)=1 / 5 x 5+1 / 3 a x 3+1 / 2 b x 2+c x$ and the formula is $x a=a^{\wedge}(1 / 2), \quad x b=b^{\wedge}(1 / 3), x c=c^{\wedge}(1 / 4)$. (3) The butterfly catastrophe mode, containing 4 sub-indexes. The model form is $\mathrm{f}(\mathrm{x})=1 / 6 \mathrm{x} 6+1 / 4 \mathrm{ax} 4+1 / 3 \mathrm{bxb}+1 / 2 \mathrm{cxc}+\mathrm{dx}$ and the formula is $x a=a^{\wedge}(1 / 2), \quad x b=b^{\wedge}(1 / 3)$, $x c=c^{\wedge}(1 / 4), \quad x d=d^{\wedge}(1 / 5)$. 
Take the Shenyang Machine Tool (SMTCL) as an example here, and all data is shown in Table 2.

Table 2 Flexibility factors of SMTCL in 2002

\begin{tabular}{ll}
\hline Company name & Shenyang Machine Tool \\
\hline Deadline & 2002 \\
Long-term liability/ Working capital & -1.132556692 \\
Inventory/Total assets & 0.092757639 \\
R\&D investment/Fixed assets & 0 \\
Inventory turnover & 1.7821 \\
Asset-liability ratio & 0.79307552 \\
Equity multiplier & 4.832681 \\
Capital structure flexibility & 0.443620376 \\
Net profit growth rate $(\%)$ & 97.9178 \\
Accounts receivable turnover & 2.4259 \\
Payable turnover ratio & 1.79 \\
Current asset turnover & 0.4962 \\
Total assets turnover & 0.2806 \\
Return on equity & 0.59 \\
Return on assets & 1.1573 \\
Ratio of profits to cost & 0.135874 \\
\hline
\end{tabular}

For indicators $\mathrm{A} 1$ and $\mathrm{A} 2$, the equations are listed below:

$X A 1=A 1^{\wedge} 1 / 2=(0.092757639)^{\wedge} 1 / 2=0.304561389, \quad X A 2=A 2^{\wedge} 1 / 3=(1.7821)^{\wedge} 1 / 3=1.212395$,

And based on the complementary relationship between the 2 indicators, the average can be reached

$A=(0.304561389+1.212395) / 2=0.758478$

For indicators B1, B2, B3 and B4, the equations are listed below:

$$
\begin{aligned}
& X B 1=B 1^{\wedge} 1 / 2=(2.4259)^{\wedge} 1 / 2=1.55753, \\
& X B 2=B 2^{\wedge} 1 / 3=(1.79)^{\wedge} 1 / 3=1.214184, X B 3=B 3^{\wedge} 1 / 4=(0.4962)^{\wedge} 1 / 4=0.839294, \\
& X B 4=B 4^{\wedge} 1 / 5=(0.2806)^{\wedge} 1 / 5=0.775564
\end{aligned}
$$

And based on the complementary relationship between the 2 indicators, the average can be reached $B=(1.55753+1.214184+0.839294+0.775564) / 4=1.096643$

R\&D flexibility $C=C 1=0$

For D1, D2, and D3, the equations are listed below:

$X D 1=D 1^{\wedge} 1 / 2=(0.79307552)^{\wedge} 1 / 2=0.890548$

$X D 2=D 2^{\wedge} 1 / 3=(-1.13255669)^{\wedge} 1 / 3=-1.04236539$

$X D 3=D 3^{\wedge} 1 / 4=(4.832681)^{\wedge} 1 / 4=1.482679$

For indicators F1 , F2 and F3, the equations are listed below:

$X F 1=F 1^{\wedge} 1 / 2=(0.0059)^{\wedge} 1 / 2=0.076811$

$X F 2=F 2^{\wedge} 1 / 3=(0.011573)^{\wedge} 1 / 3=0.226194$

$X F 3=F 3^{\wedge} 1 / 4=(0.001359)^{\wedge} 1 / 4=0.191992$

The average $\mathrm{F}$ can be reached, $F=(0.076811+0.226194+0.226194 / 3=0.164999$

Based on the above, one can draw a conclusion that, in 2002, the resources flexibility is 0.758478 , the operation flexibility is 1.096643 , the capital structure flexibility is 1.482679 and the market flexibility is 0.191992 . Part of the sample indexes is shown in Table 3. 
Table 3 Part of the sample indexes

\begin{tabular}{lccccccc}
\hline Company name & Year & RDF & \multicolumn{1}{c}{ RF } & CSF & \multicolumn{1}{c}{ OF } & MF & \multicolumn{1}{c}{ NPG } \\
\hline SMTCL & 2002 & 0.0000 & 0.758478 & 0.443620376 & 1.096643 & 0.164999 & 0.979178 \\
JND Engine & 2002 & 0.0000 & 0.808475 & 0.711189258 & 1.249054 & 0.497609 & 1.023254 \\
CQCA Auto & 2002 & 0.0000 & 1.051438 & 0.841825114 & 1.903565 & 0.541978 & 2.777757 \\
FC Co. & 2002 & 0.0000 & 0.90116 & 0.560619463 & 1.93064 & 0.372925 & 6.379875 \\
Yinhe Co. & 2002 & 0.0000 & 0.738368 & 0.946748986 & 1.263202 & 0.423483 & -0.263399 \\
JH Engine & 2002 & 0.0000 & 1.009685 & 0.63902844 & 1.388828 & -0.38086 & -2.684566 \\
\hline
\end{tabular}

Regression results analysis

The regression results and analysis. Using Eviews6.0 to estimate the variable parameterequation and part of the results is shown in Table 4:

Table 4 Part of theregression results

\begin{tabular}{lllll}
\hline Variables & Coefficient & Error statistics & T-Statistic & P-Value \\
\hline C & -7.936338 & 9.665277 & -0.821119 & 0.4128 \\
CQCA AutoRDF & 1381.865 & 471.8971 & 2.928319 & 0.0039 \\
CASC RDF & 41.92755 & 109.9309 & 0.381399 & 0.7034 \\
KMYNRDF & 87.21979 & 104.0062 & 0.838602 & 0.4030 \\
CQCA AutoRF & -33.15372 & 48.46590 & -0.684063 & 0.4950 \\
CASC RF & 17.73258 & 33.91437 & 0.522863 & 0.6018 \\
KMYNRF & 239.6451 & 58.25184 & 4.113949 & 0.0001 \\
CQCA AutoCSF & 68.64005 & 7.904289 & 8.683899 & 0.0000 \\
CASC CSF & -25.78008 & 78.17447 & -0.329776 & 0.7420 \\
KMYNCSF & 0.428999 & 25.49208 & 0.016829 & 0.9866 \\
CQCA AutoOF & 3.299243 & 3.872609 & 0.851943 & 0.3956 \\
CASC OF & -14.45928 & 38.65623 & -0.374048 & 0.7089 \\
KMYNOF & -78.67891 & 33.20964 & -2.369159 & 0.0191 \\
CQCA AutoMF & 73.13290 & 33.77779 & 2.165118 & 0.0319 \\
CASC MF & 29.06673 & 10.95160 & 2.654108 & 0.0088 \\
KMYN MF & -36.62990 & 20.82525 & -1.758917 & 0.0806 \\
CQCA AutoC & -59.02292 & & & \\
CASCC & 17.96708 & & & \\
KMYN C & -67.85254 & & & \\
\hline The & & & & \\
\hline
\end{tabular}

The results of the regression estimation is shown in Table 5 .

Table 5 Regression estimation results

\begin{tabular}{ll}
\hline Inspection & Observed value \\
\hline R square & 0.782190 \\
Adjusted Rsuqare & 0.520536 \\
F-statistic & 2.989400 \\
P-value (F-statistic) & 0.000000 \\
Durbin-Watson statistic & 3.010380 \\
\hline
\end{tabular}

$\mathrm{R}$ square is 0.782190 , which shows that the equations have a highcredibility $78.22 \%$; and the $\mathrm{P}$-value 0.000 is below 0.05 , so the null hypothesis is accepted at the $5 \%$ level. The Durbin-Watson statistic, $\mathrm{D}=3.01$, is close to non-autocorrelation critical value, so the equations don't have heteroscedasticity. In conclusion, all the test values show that the equations have high credibility, without heteroscedasticity.

\section{Conclusion}

This article selects 31 companies in engineering and electronic manufacturing as study object and we can come to the conclusion that the business flexibility factors contribute to business performance, in all the factors, RDF and MF are the most two factors while CSF is the least one. The conclusion not only enriches the business performance and enterprise strategy theory but also supplies the empirical support for the 
development of most manufacture enterprises of construction machinery, and has a great significance for the development of Chinese manufacturing industry.

It is a new attempt to quantify the flexibilities by catastrophe progression method, which is very important to the long-term development and strategy adjustment of enterprises. However, the credibility of the equation is not high enough, and whether there is a more complicated relationship between flexibilities and business performance and how should the enterprise adjust the strategy are remained to be solved.

\section{References}

[1] Beach R,Muhlemann A P,Price D H R,Paterson A, Sharp J A.A Review of Manufacturing Flexibity[J].European Journal of Oprational Research,2000,(122):41-57

[2] KRAATZMS, ZAJACEJ.How Organizational Resources Affect Strategic Change and Performance in Turbulent Environments Theory and Evidence[J].Organization Science,2001,12(5):632-657

[3] Mark Doms\& Eric J. Bartelsman.Understanding Productivity: Lessons from Longitudinal Microdata[J]Journal of Economic Literature, American Economic Association,2000,38(3): 569-594 